Mental Health Research Institute, The University of Michigan

\title{
Behavioral Effects of Chronic Administration of Psychoactive Drugs to Anxious Patients*
}

\author{
By \\ Leonard Uhr, Johy C. Polfakd and James G. Miller
}

(Received May 14, 1959)

Previous experiments (KELLY etal. 1958a, b; MARqUIs etal.; Sмiтн et al.) have studied effects of meprobamate and other psychoactive drugs on the objectively measured behavior of normal subjects after acute and after chronic administration of the drug treatments. The present experiment investigates chronic drug effects on a sample of patients psychiatrically diagnosed as anxiety neurotics. This, then, allows for extension of our previous findings to a new group of potential drug users - the more disturbed outpatient, of psychiatrist or general practitioner, who is likely to be treated for protracted periods under close medical supervision.

The driving, vision, and attention tests developed and used previously were again employed in this experiment, along with new tests that appeared promising as anxiety-sensitive indicators. In addition to data from the objective behavioral tests, two other types of data were collected - psychiatric assessments on a number of variables, and check-list ratings both by the patients and by a close friend.

\section{Method}

Subjects. Thirty-eight paid volunteers, ranging in age from 21 to 41 years, were chosen as subjects for the present study of whom thirtytwo, including 15 men and 17 women, completed the experiment. This total included 23 patients who were diagnosed as anxiety neurotics on the basis of a psychiatric interview and work-up, plus nine normal controls. Patients were recruited from three sources: a) A general practi-

* The authors wish to thank Mr. Gershom Morningstar for conducting the behavioral tests, Drs. RaLPH W. GeraRd and E. Lowell KeLly for consultation in planning and designing the experiment, Mrs. Mona Morningstar and Messrs. Cameron Yerian and Arthur Platz for help in coding, and Dr. George Fink and The University of Michigan Health Service for referring patients. Partial support and drugs for this study were supplied by the United States Food and Drug Administration, and part from USPHS Grant No. M-1871, Dr. JAMeS G. Mrlugr, Principal Investigator. 
tioner in private practice referred a series of his patients, whom he diagnosed as anxious, and whom he would normally have treated with psychoactive drugs. b) One hundred and twenty subjects who volunteered in response to a newspaper advertisement were pre-screened with the Taylor Manifest Anxiety Scale (TAYLOR). This was the source for the normal control subjects. c) The Student Health Service of The University of Michigan referred students who, in the opinion of the Health Service psychiatrists, manifested neurotic anxiety. These three sources were merely the screening channels of entry into the study; all final diagnoses were made by the psychiatrist directly involved, so that criteria for diagnosis were constant for all patients.

Two of the six who did not complete the experiment were in the anxious group. One of these patients was dropped because of the intensity of his pathology. (This had been diagnosed prior to the study, and clearly was in no way connected with the drug treatments.) The other patient, along with the three normal subjects, dropped out for financial reasons - either because he no longer needed the money, or because he was forced to move out of town to take a job. The fourth normal dropped out because of psychological effects that may have been related to drug treatment (Tranquil).

Dosages and Treatments. After the patient had been interviewed by the psychiatrist and chosen for the study, the following regime was instituted: a first behavioral test session was run under the effects of a single oral dose of $15 \mathrm{mg}$. of phenobarbital, given one-half hour before testing began. No attempt was made to balance the ordering of this barbiturate test with the rest of the study. It was deemed more desirable to use this testing session as pre-training on those tasks for which practice and familiarization might play a part, and to make the actual comparison between phenobarbital and other drug treatments only on those tests clearly without practice effects.

Three 21-day periods of pill administration now began, one for each treatment. The ordering of the treatments was balanced out across the entire group (and within the normal and neurotic sub-groups). Pills were put in unlabelled bottles by a technician not connected with the experiment, so that neither experimenter nor patient knew what treatment was being given. However, one innovation, introduced to eliminate some of the problems of placebo effects, made possible an unforeseen type of unblinding of the experimenters. Rather than administer the three different treatments in the same pill form, which might have maximized placebo effects for the first treatment and almost eliminated them for the next two treatments, the pills were presented in three different forms, matched for size but with the differences between these forms 
maximized. These forms, however, were identical for a single drug, so that if the experimenter were told by the patient something that identified the shape of the pill, he was thus informed of the drug treatment. This happened in seven of the 96 testing sessions. Because of the objective nature of the behavioral tests, which are not influenced by experimenter bias, this should have had no effect on the behavioral test phase of the study. But the psychiatric assessment phase of the study was subject to the same partial unblinding (in six of 87 interviews), and in this case we can be less certain of the effects.

Daily dosages were as follows: a) $1600 \mathrm{mg}$. of meprobamate, b) five Tranquil tablets (the maximum recommended daily dose), and c) five large placebo tablets. Tranquil is a combination of a large number of drugs, but its effective components are chiefly bromides. Five tablets contain the following amounts: sodium bromide $0.485 \mathrm{gms}$., potassium bromide 0.97 gms., ammonium bromide 0.164 gnıs. This drug was tested because it had been placed on the market as an over-the-counter drug whose name connoted tranquilizing effects. Thus we compared a tranquilizer with a bromide compound in addition to determining the effects of each in relation to a placebo.

At the end of each of the three treatment periods, patients were seen at two separate sessions: a) for testing on the driving battery, orthorater and other behavioral tests, and b) for a psychiatric interview (during which $10 \mathrm{ce}$. of blood was taken, for analysis of bromide level). All behavioral testing was done by the same technician; all interviews were conducted by the same psychiatrist. The third phase of the study was conducted as follows: Every seven days the patient mailed in a self-report rating schedule, thus giving three weekly checks on the action of each drug treatment. In addition, all patients had a spouse, close friend, or roommate (chosen by the patient) mail in similar rating forms. These ratings thus allowed for analyses of subjectively felt changes, for changes observed by someone in close daily contact with the patient, and for discrepancies between inner feelings and behavior observable by another.

Objective Behavioral Test Battery. The objectively measured variables were scored from various aspects of the patient's performance on nine different behavioral tests. Twenty-seven variables were scored directly, and three variables were derived as difference or ratio scores from these basic variables. These tests, together with the scores obtained on each, are described below.

A. Driver Test (7 scores). The American Automobile Association's "Auto Trainer" was used. The patient operated the trainer by working 
the controls of a conventional shift automobile. A treadmill-like belt about 10 feet long, painted to resemble a winding road, extends in front of the control unit. A model car, connected to the steering wheel and operated by the subject, rests on the belt. The patient's job is to keep the car on the road and to brake the car whenever a red light appears. (For a more complete description of this apparatus, see MARQUIS et al. 1957).

Patients were given trials as follows: 20 revolutions of the belt at a fixed low speed; 20 at a fixed high speed; and 20 at a speed controlled by the subject. Six reaction-time determinations were interspersed irregularly through the first two trials.

Accuracy, or proficiency, of driving in this situation is measured in terms of the patient's ability to keep the car on the road. Three accuracy scores were obtained: at the fixed low speed, at the fixed high speed, and at the variable patient-controlled speed. A "speed" score was also obtained, the time required for the trial when the patient was controlling his own speed. A derived judgment score was also computed - the ratio of the difference between the accuracy score at low fixed speed and the accuracy score at patient-controlled speed, divided by the time score.

B. Vision Tests (7 scores). Tests of the various components of vision that might be affected by psychoactive drugs were conducted on the Bausch and Lomb master model ortho-rater, an instrument designed to control illumination, distance and presentation of visual stimuli (KELLY et al. 1958a; MarquIs et al.). Acuity was determined for both far and near vision; depth perception was determined for distant vision only. Vertical and lateral phorias for both near and far vision were also measured. (For a more complete description, see KeLLy et al. 1958a.)

C. Kinesthetic Figural After-Effect (1 score). This apparatus, originally developed by KöHLER and WALLACH (KöHLER and WALLACH), was used in an attempt to follow up evidence that kinesthetic figural aftereffects are indications of personality disorders. EYSENCK has found that hysterics, as compared with dysthymics (anxious patients), more quickly developed figural after-effects which were stronger and more persistent. KLein and Krecr found much the same effects for brain injured patients, as compared with normal subjects (KLEIN and $\mathrm{K}_{\mathrm{RECH}}$ 1952).

The patient is blindfolded for this test, so that he never sees the apparatus. His task is to judge the width of a $1 \frac{1}{2}{ }^{\prime \prime}$ block of wood felt between the thumb and forefinger of his left hand. The judgment is made both before and after an after-effect is induced. (For a more complete description, see KeLLy et al. 1958a.) Three scores are obtained: 
1. mean original judgment, 2. mean after judgment, and 3. mean aftereffect change (difference in judgment from 1 to 2). Only the second and third scores, which measure the after-effect, were analyzed.

D. Judgment of Lines Test (2 scores). This test, which forms a part of CatTEll's Objective-Analytic Test battery (CATtell 1955), is said to be an objective measure of general anxiety. The patient is instructed to mark an $\mathrm{X}$ to show which of two paired lines is the longer, or to indicate that both are of equal length. This is a timed test, in which 30 seconds are allowed for each of four pages of lines to be compared, each page containing 20 pairs of lines. Two scores are obtained: 1 . number completed, and 2. per cent accuracy.

E. Tempos and Time Estimations (6 scores). First, the patient's fastwalking rate is determined. Then the patient is asked to set a metronome at the rate he prefers (Kelly et al. 1958a). Time estimations, shown to be drug-sensitive by Stetnberg (1955) and KLEemerr (1956), were then taken. The patient was asked to estimate a lapse of 20 seconds of time : first, without attempting to count seconds, while a metronome beat at the rate of 100 per minute; second, while counting to himself (Uhr and Miller, in press). Finally, the patient was asked to set the metronome as closely as possible to correspond to two rates - first, 50 beats per minute, and second, 180 beats per minute (UHR and Mrtuer, in press).

F. Attention Span (2 scores). Digit span forward and digit span backward were both tested and scored. These are simple measures of attention span and short-term memory that have been shown by Kornetsky, Humphries, and Evarts to be sensitive to psychoactive drugs. This test was administered according to standard WechslerBellevue procedures (WeChSLER 1944).

G. Muscular Persistence (3 scores). Strength and persistence were tested using a hand dynamometer. The patient was asked to squeeze the dynamometer as hard as he could three times. The dynamometer needle was then set at $60 \%$ of his third squeeze, and the patient was asked to hold the dynamometer needle steady at this point for as long as he was able. This test has been said to be sensitive to anxiety (HAMILTON 1955). A second score was analyzed - the strength of pull on the first trial - for a gross check on muscle strength. A third score was derived - the difference between strength of pull on the first trial and the second trial - as a test of level of aspiration-related motivation.

H. Hyperventilation Test (2 scores). In this test, the patient is first asked to hold his breath as long as he can. He is next told to breathe deeply for 30 seconds. He is then to hold his breath as long as he can. 
This test has been shown by Mrrsky et al. (1946) and by Frtkidman (1947) to discriminate between normals and neurotics. 'Two scores were analyzed: the difference in length of time breath was held before and after hyperventilation, and the absolute length of time breath was held after hyperventilation.

Psychiatric Interview. Fifteen aspects of the patient's reactions to the drug treatments were objectified and tested for the significance of drug effects. The psychiatrist who interviewed patients at the end of each drug period developed his own quantification methods and converted his interview notes and work-up into 3-point ratings on each of the scales he devised. These included three general types of scales: a) relatively objective self-observations reported by the patient: skin changes, physical changes, daytime sleepiness, night sleep, and appetite; b) relatively subjective self-observations reported by the patient: reactions to the treatment, restfulness, changes in physical effort required, activity of the drug, and liking for the drug; and e) ratings of the patient by the psychiatrist: concentration, retention, motivation, tension, improvement. This is a rough trichotomy; it should be remembered that all three types of source material for these ratings were filtered through the psychiatrist, who synthesized and made a elinical judgment of his interview material, and then quantified these judgments on 3-rating scales of the different behaviors observed. Complete data for this phase of the study were collected for 29 people.

Blood Bromide Level. A sixteenth measure was made from blood collected at the time of the psychiatric interview - the determination of blood bromide level, in milligrams per 100 cubic centimeters of blood. Complete data for this part of the study were collected for 26 people.

Weekly Ratings by Self and by 0ther. All patients filled out and returned a self-report schedule every seven days, or three times during each of the three treatment periods. In addition, the spouse, roommate, or intimate friend separately filled out and returned two schedules, one characterizing himself, the other characterizing the patient in the experiment.

Fifteen variables, representing only a portion of these data, have been scored and analyzed at this time. Because of the magnitude of the analysis task, only the third report on each drug, which should give the cumulative effect of the drug treatment, was used. The first and second reports would allow for further analysis of the weekly time response effects of the treatment.

Semantic Differential self-reports, as modified and used in previous drug studies (KeLLY et al. 1958a), were scored for the three factors 
identified by OsGood (1957): 1. evaluative, 2. activity, and 3. potency. An adjective check list was derived from two sources. First, a check list designed by Nowlis (Nowlis and Green 1957) was shortened by taking the five adjectives with the highest loadings on each of the eight factors identified by him. An additional scale was constructed from adjectives that subjects in the study of chronic drug effects conducted by KeLly et al. (1958a) had most frequently used to characterize their subjective changes.

Only four of the nine scales - those that appeared to be most closely related to drug effects - were scored and analyzed. These scales were 1. Concentration, 2. Activation vs. Deactivation, 3. Anxiety, and 4. Subject-Reported Drug Effects. These four scales were each scored for the following: a) the patient's rating of himself, b) the other's rating of the patient, and c) the discrepancy between the patient's and the other's rating of the patient.

\section{Results}

Objective Behavioral Tests. Table 1 presents the mean performances on each of the objectively scored behavioral tests under each of the continued drug treatments, for the total group of 32. (The effects of the acute administration of phenobarbital will be reported elsewhere.)

The difference between the mean performance (Table l) under one treatment as compared to another, when evaluated in terms of the standard error (an estimate of the amount these means might differ as a result of chance alone), gives the magnitude of the difference in effect

Table 1. Mean performance under meprobamate, Tranquil, and placebo on objective behavioral tests

\begin{tabular}{c|c|c|c|c}
\hline & Test & Vari- & \multicolumn{2}{|c}{ Mean performance under } \\
\cline { 2 - 4 } & able & mepro- & Tranquil & placebo \\
\hline
\end{tabular}

A. Driving

\begin{tabular}{|c|c|c|c|c|}
\hline 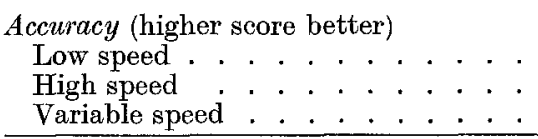 & $\begin{array}{l}1 . \\
2 . \\
3 .\end{array}$ & $\begin{array}{l}246.6 \\
189.3 \\
207.0\end{array}$ & $\begin{array}{l}253.5 \\
193.0 \\
206.9 \\
\end{array}$ & $\begin{array}{l}250.4 \\
203.6 \\
215.1\end{array}$ \\
\hline $\begin{array}{l}\text { Time: } \\
\quad \text { Variable speed (higher score better) }\end{array}$ & 4. & 301 & 284 & 300 \\
\hline 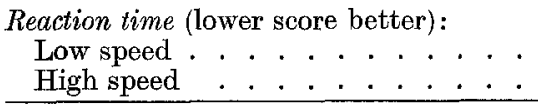 & $\begin{array}{l}5 . \\
6 . \\
\end{array}$ & $\begin{array}{l}24.6 \\
22.8\end{array}$ & $\begin{array}{l}23.9 \\
22.9 \\
\end{array}$ & $\begin{array}{l}23.0 \\
20.9\end{array}$ \\
\hline Judgment (lower score better): & 7. & 1.69 & 2.15 & 1.44 \\
\hline
\end{tabular}


Table 1 (continued)

\begin{tabular}{|c|c|c|c|c|}
\hline \multirow[b]{2}{*}{ Test } & \multirow{2}{*}{$\begin{array}{l}\text { Vari- } \\
\text { able } \\
\text { No. }\end{array}$} & \multicolumn{3}{|c|}{ Mean performance under } \\
\hline & & $\begin{array}{l}\text { mepro- } \\
\text { bamate }\end{array}$ & Tranquil & placebo \\
\hline
\end{tabular}

B. Vision (higher score better)

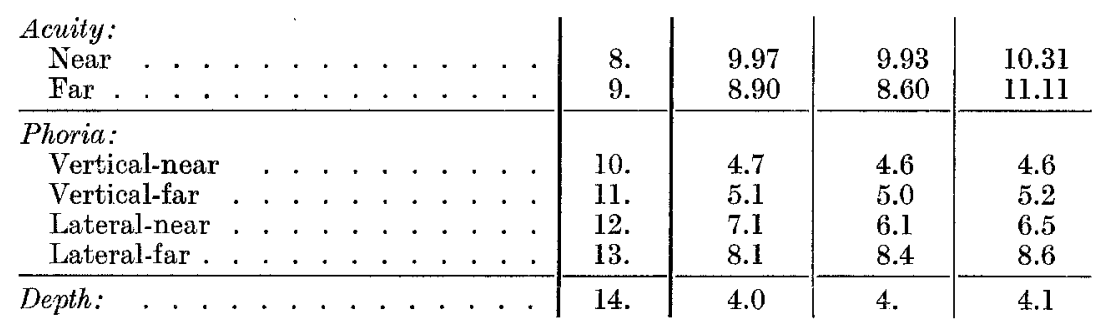

C. Kinesthetic after-effect (higher seore better)

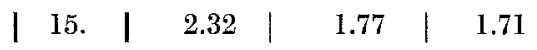

D. Line judgment (higher score better)

\begin{tabular}{lllll|l|l|l|l} 
Completed . . . . . . . . . . . . & 16. & 77.7 & $\mathbf{7 7 . 3}$ & $\mathbf{7 8 . 2}$
\end{tabular}

E. Tempos and times

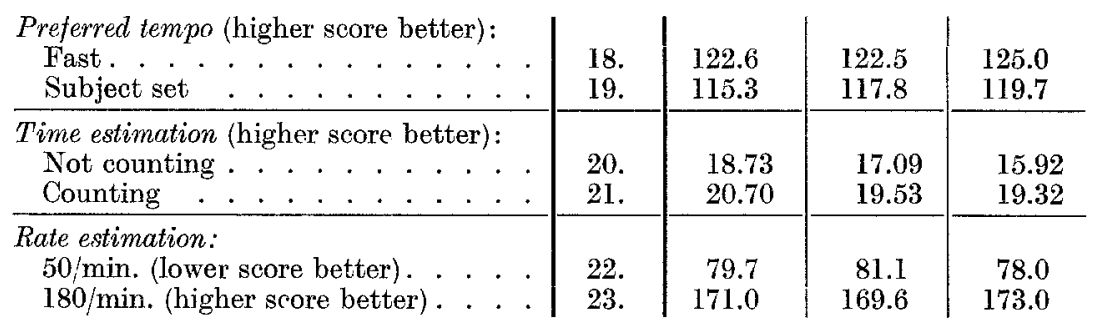

F. Digit span (higher score better)

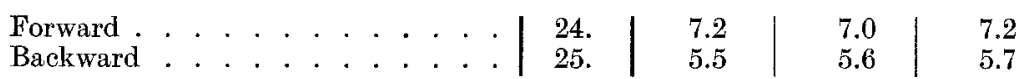

G. Muscular persistence (higher score better)

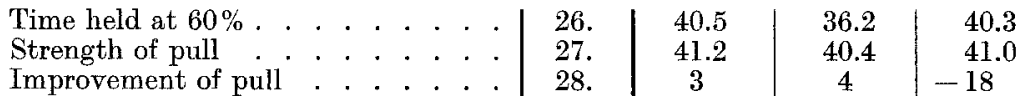

H. Hyperventilation (higher score better)

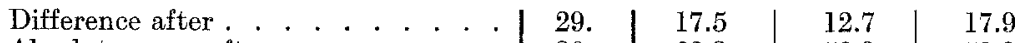

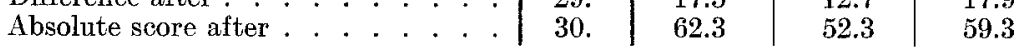

between the two treatments, and the probability that this difference is a dependable one, and not the result of mere chance. Table 2 presents 
Table 2. Magnitude and significance of differences in performance on the objective behavioral tests, for the different contrasts in treatments

[Plus value (no sign) indicates that performance was better under first treatment.]

\begin{tabular}{c|c|c|c|c|c}
\hline \multirow{2}{*}{ Test } & $\begin{array}{c}\text { Vari- } \\
\text { able } \\
\text { No. }\end{array}$ & \multicolumn{3}{|c|}{$\begin{array}{c}\text { Significance of difference } \\
\text { (C.R.) in performance under }\end{array}$} \\
\cline { 3 - 5 } & $\begin{array}{c}\text { veprobamate } \\
\text { vs. placebo }\end{array}$ & $\begin{array}{c}\text { Tranquil } \\
\text { vs. placebo }\end{array}$ & $\begin{array}{c}\text { meprobamate } \\
\text { vs. Tranquil }\end{array}$ \\
\hline
\end{tabular}

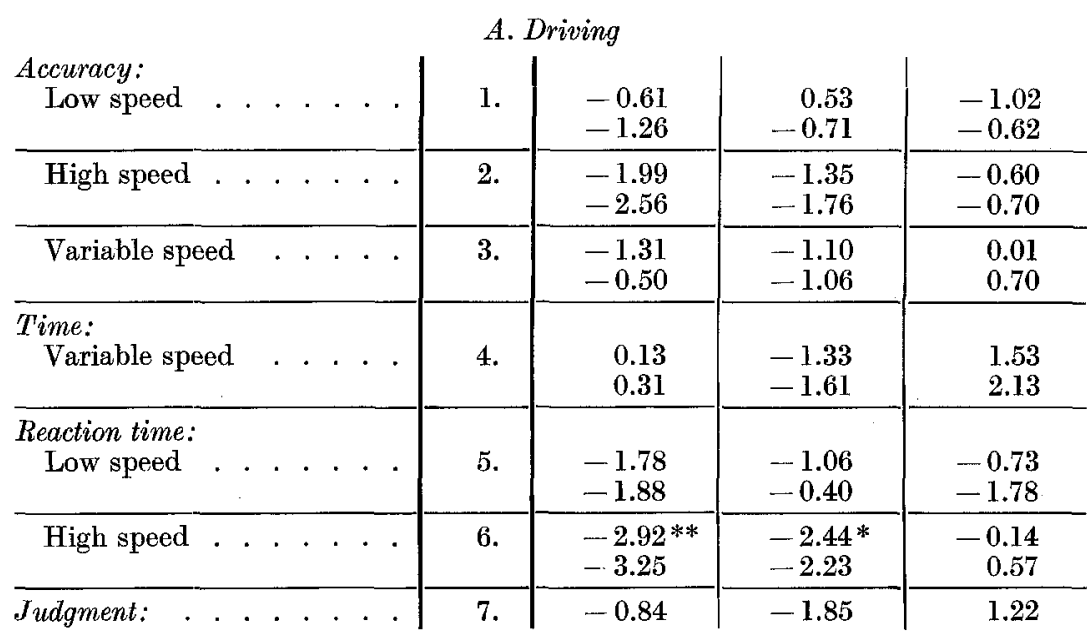

B. Vision

\begin{tabular}{|c|c|c|c|c|}
\hline $\begin{array}{l}\text { Acuity: } \\
\quad \text { Near . . . . . . . . }\end{array}$ & 8. & $\begin{array}{r}-1.82 \\
-1.37 \\
\end{array}$ & $\begin{array}{l}-1.96^{*} \\
-1.17 \\
\end{array}$ & $\begin{array}{r}0.24 \\
-0.11 \\
\end{array}$ \\
\hline Far. . . . . . & 9. & $\begin{array}{l}-1.05 \\
-1.12 \\
\end{array}$ & $\begin{array}{r}-1.20 \\
-1.20 \\
\end{array}$ & $\begin{array}{l}1.38 \\
0.70\end{array}$ \\
\hline $\begin{array}{l}\text { Phoria: } \\
\text { Vertical-near }\end{array}$ & 10. & $\begin{array}{l}0.77 \\
1.82 \\
\end{array}$ & $\begin{array}{l}0.00 \\
0.67 \\
\end{array}$ & $\begin{array}{l}0.63 \\
0.63 \\
\end{array}$ \\
\hline Vertical-far & 11. & $\begin{array}{r}-0.71 \\
0.00\end{array}$ & $\begin{array}{l}-1.33 \\
-1.33\end{array}$ & $\begin{array}{l}0.91 \\
1.43\end{array}$ \\
\hline Lateral-near & 12. & $\begin{array}{l}1.58 \\
2.00\end{array}$ & $\begin{array}{l}-1.33 \\
-1.16\end{array}$ & $\begin{array}{l}2.33 * \\
2.50\end{array}$ \\
\hline Lateral-far & 13. & $\begin{array}{l}-0.82 \\
-0.59\end{array}$ & $\begin{array}{r}-0.95 \\
0.00\end{array}$ & $\begin{array}{l}-0.57 \\
-0.67\end{array}$ \\
\hline ...... & 14. & $\begin{array}{l}-0.45 \\
-0.87\end{array}$ & $\begin{array}{l}-0.42 \\
-0.43\end{array}$ & $\begin{array}{r}0.00 \\
-0.32\end{array}$ \\
\hline
\end{tabular}

C. Kinesthetic after-effect
| 15.
0.80
0.09
0.82

D. Line judgment

Completed

16. $\quad-0.77$

0.14

$-1.17$

0.55

1.25 
Table 2 (continued)

\begin{tabular}{|c|c|c|c|c|}
\hline \multirow{2}{*}{ Test } & \multirow{2}{*}{$\begin{array}{c}\text { Vari- } \\
\text { able } \\
\text { No. }\end{array}$} & \multicolumn{3}{|c|}{$\begin{array}{l}\text { Significance of difference } \\
\text { (C.R.) in performance under }\end{array}$} \\
\hline & & $\begin{array}{l}\text { meprobamate } \\
\text { vs. placebo }\end{array}$ & $\begin{array}{c}\text { Tranquil } \\
\text { vs. placebo }\end{array}$ & $\begin{array}{l}\text { meprobamate } \\
\text { vs. Tranquil }\end{array}$ \\
\hline Per cent correct & 17. & $\begin{array}{l}1.13 \\
0.75\end{array}$ & $\begin{array}{l}0.34 \\
0.28\end{array}$ & $\begin{array}{l}0.62 \\
0.25\end{array}$ \\
\hline
\end{tabular}

E. Tempos and times

\begin{tabular}{|c|c|c|c|c|}
\hline $\begin{array}{l}\text { Preferred tempo: } \\
\text { Fast . . . . }\end{array}$ & 18. & $\begin{array}{l}-0.96 \\
-0.61 \\
\end{array}$ & $\begin{array}{l}-1.09 \\
-2.38 \\
\end{array}$ & $\begin{array}{l}0.03 \\
1.20\end{array}$ \\
\hline Subject set . . . . & 19. & $\begin{array}{l}-0.63 \\
-0.11 \\
\end{array}$ & $\begin{array}{r}-0.28 \\
0.13 \\
\end{array}$ & $\begin{array}{l}-0.31 \\
-0.21 \\
\end{array}$ \\
\hline $\begin{array}{l}\text { Time estimation: } \\
\text { Not counting . . }\end{array}$ & 20. & $\begin{array}{l}3.82 * * \\
3.32\end{array}$ & $\begin{array}{l}1.57 \\
1.25\end{array}$ & $\begin{array}{l}2.93 * * \\
2.10\end{array}$ \\
\hline Counting & 21 . & $\begin{array}{l}1.55 \\
1.66\end{array}$ & $\begin{array}{l}0.32 \\
1.31\end{array}$ & $\begin{array}{l}1.52 \\
0.97\end{array}$ \\
\hline $\begin{array}{l}\text { Rate estimation: } \\
50 / \text { min. . . . . . }\end{array}$ & 22. & $\begin{array}{r}-0.40 \\
0.50 \\
\end{array}$ & $\begin{array}{r}-0.59 \\
0.23 \\
\end{array}$ & $\begin{array}{l}0.35 \\
0.94\end{array}$ \\
\hline 180/min. . . . . . . & 23. & $\begin{array}{l}-0.35 \\
-0.33\end{array}$ & $\begin{array}{l}-0.54 \\
-0.15\end{array}$ & $\begin{array}{r}0.35 \\
-0.30\end{array}$ \\
\hline
\end{tabular}

\section{F. Digit span}

\begin{tabular}{|c|c|c|c|c|}
\hline Forward . . . . . & 24. & $\begin{array}{r}0.00 \\
-\quad 0.48 \\
\end{array}$ & $\begin{array}{l}-1.18 \\
-0.43\end{array}$ & $\begin{array}{l}0.77 \\
0.00\end{array}$ \\
\hline Backward & 25. & $\begin{array}{r}-1.18 \\
-0.45\end{array}$ & $\begin{array}{r}-0.53 \\
0.00\end{array}$ & $\begin{array}{l}-0.56 \\
-0.48\end{array}$ \\
\hline
\end{tabular}

\section{G. Muscular persistence}

\begin{tabular}{r|r|r|r|r} 
Time held at 60\% . . & 26. & 0.05 & -1.03 & 1.48 \\
& & 0.79 & -0.10 & 1.16 \\
\hline Strength of pull . . . & 27. & 0.19 & -0.52 & 0.69 \\
& & 0.20 & -0.37 & 0.54 \\
\hline Improvement of pull . . & 28. & 1.40 & 1.91 & -0.98
\end{tabular}

\section{H. Hyperventilation}

\begin{tabular}{l|l|l|l|l} 
Difference after . . . & 29. & -0.19 & -1.65 & 1.57 \\
\hline Absolute score after . . & 30. & 1.17 & $-2.27^{*}$ & $2.83 * *$ \\
1.00 & -2.59 & 2.92
\end{tabular}

1. The first line for each variable presents the Critical Ratio for the total group $(N=32)$. The second line for the anxious subgroup $(N=23)$.

2. Data on derived scores were not analyzed for the anxious subgroup. Significant C.R.'s are starred only for the total group (the top lines).

* Significant beyond the $5 \%$ level of probability.

** Significant beyond the $1 \%$ level of probability.

Psychopharmacologia, Bd. 1 
the results of this evaluation - the magnitudes of the critical ratios for the comparisons between treatments: 1. meprobamate vs. placebo, 2. Tranquil vs. placebo, 3. meprobamate vs. Tranquil. A plus value (no sign) indicates that performance was better under the first as contrasted with the second treatment in the comparison. The first line for each variable gives the Critical Ratio for the total sample $(N=32)$, the second line for the subsample of 23 anxious patients.

Table 3. Mean psychiatric ratings of patients under meprobamate, Tranquil, and placebo

(The scale name characterizes the high end of the scale.)

\begin{tabular}{|c|c|c|c|c|}
\hline \multirow{2}{*}{\multicolumn{2}{|c|}{ Rating dimension }} & \multicolumn{3}{|c|}{ Mean rating under } \\
\hline & & $\begin{array}{l}\text { mepro- } \\
\text { bamate }\end{array}$ & $\begin{array}{l}\text { Tran- } \\
\text { quil }\end{array}$ & pla- \\
\hline 1. Marked reaction & & 2.4 & 2.3 & 1.8 \\
\hline 2. Marked daytime sleepiness & & 1.9 & 1.8 & 1.3 \\
\hline 3. Longer nighttime sleep. . & & 2.4 & 2.4 & 1.8 \\
\hline 4. More restfulness . . & & 2.4 & 2.2 & 2.0 \\
\hline 5. Better concentration & & 1.9 & 1.6 & 1.8 \\
\hline 6. Better retention . . & & 2.0 & 1.7 & 1.8 \\
\hline 7. Better motivation . . . . & & 1.7 & 1.6 & 1.8 \\
\hline 8. Less physical effort required. & & 1.8 & 1.8 & 2.0 \\
\hline 9. Less tension . . . . . & . & 2.4 & 2.1 & 1.9 \\
\hline 10. Increased appetite . & & 1.7 & 1.7 & 2.0 \\
\hline 11. Marked skin change. & & 0.0 & 0.2 & 0.0 \\
\hline 12. Severe physical change & & 0.1 & 0.3 & 0.0 \\
\hline 13. Drug was active. . & & 2.1 & 2.0 & 1.6 \\
\hline 14. Subject feels better & & 2.5 & 2.3 & 2.3 \\
\hline 15. Subject likes drug . & & 2.1 & 1.7 & 2.1 \\
\hline
\end{tabular}

Psychiatric Evaluation. Table 3 presents, for the total group (29) for whom complete data from the psychiatric evaluations are available, the mean score on each of the 15 aspects of behavior quantified and rated by the interviewing psychiatrist.

Table 4 presents the significance of the differences between the ratings in Table 3 after each drug treatment as compared with each other treatment. A plus value (no sign) indicates a more desirable rating on that scale for the first as contrasted with the second treatment in the comparison.

Blood Bromide Levels. Table 5 presents the mean blood bromide level under each of the three treatments, and the significance of the differences in these levels between the three combinations of treatment $N=26)$.

Tranquil treatment led to a highly significant rise in blood bromide evel, and to occasional skin reactions. 
Self and 0ther Rating Sehedules. Table 6 presents the mean scores on a) the seven variables scored from self-report materials (after three weeks of the drug), b) the four variables scored from ratings of the patient made by another person, and c) the four difference scores derived

Table 4. Magnitude and significance of differences in psychiatric evaluations for the different contrasts in treatment

[Plus value (no sign) indicates better rating under first treatment.]

\begin{tabular}{|c|c|c|c|}
\hline \multirow{2}{*}{ Rating dimension } & \multicolumn{3}{|c|}{ Significance of difference (C. R.) under } \\
\hline & $\begin{array}{l}\text { meprobamate } \\
\text { vs. placebo }\end{array}$ & $\begin{array}{c}\text { Tranquil } \\
\text { vs. placebo }\end{array}$ & $\begin{array}{l}\text { meprobamate } \\
\text { vs. Tranquil }\end{array}$ \\
\hline 1. Marked reaction . . . . . . . & $3.16^{* *}$ & $2.00^{*}$ & -0.40 \\
\hline 2. Marked daytime sleepiness . . . & $-3.16 * *$ & $\begin{array}{l}-3.13 * * \\
-5.38\end{array}$ & -0.50 \\
\hline 3. Longer nighttime sleep & $\begin{array}{l}4.29 * * \\
2.50 \\
\end{array}$ & $\begin{array}{l}4.29 * * \\
3.13\end{array}$ & $\begin{array}{c}0.00 \\
-\end{array}$ \\
\hline 4. More restfulness $. \quad . \quad . \quad . \quad . \quad . \quad$. & $3.33 * *$ & 1.54 & 1.43 \\
\hline 5. Better concentration . . . . . & 0.91 & -1.54 & $2.00 *$ \\
\hline 6. Better retention . . . . . . & $2.00 *$ & -0.91 & $3.00 * *$ \\
\hline 7. Better motivation . . . . . . & -0.77 & -1.54 & 0.77 \\
\hline 8. Less physical effort required . . & $-2.86 * *$ & $-2.86^{*}$ & 0.00 \\
\hline 9. Less tension . . . . . . . & $3.13 * *$ & 1.33 & 1.67 \\
\hline 10. Increased appetite . . . . . & $-2.31 *$ & $-2.14 *$ & 0.00 \\
\hline 11. Marked skin change. . . . . . & 0.00 & -1.82 & $2.50 *$ \\
\hline 12. Severe physical change & 1.43 & 1.36 & 0.87 \\
\hline 13. Drug was active & $\begin{array}{l}2.63 * * \\
1.67 \\
\end{array}$ & $\begin{array}{l}2.11 * \\
-\end{array}$ & $\begin{array}{c}0.67 \\
- \\
\end{array}$ \\
\hline 14. Subject feels better . . . . . . & 0.91 & 0.00 & 1.00 \\
\hline 15. Subject likes drug. . & 0.00 & -1.90 & $1.38^{\circ}$ \\
\hline
\end{tabular}

1.C.R.'s for the neurotic subgroup are reported only when they are discrepant from the C.R.'s for the total group.

2. Significant C.R.'s are starred only for the total group.

* Significant beyond the $5 \%$ level of probability.

** Significant beyond the 1\% level of probability.

to indicate the magnitude of discrepancies between subjectively felt reactions and the degree to which these reactions are observable by another person.

Table 7 presents the significance of the differences between the scores in Table 6 after each three-week drug treatment as compared with each other treatment. A plus value (no sign) indicates a more desirable rating on the first as contrasted with the second treatment. 
Table 5. Analysis of blood bromide levels

A. Milligrams of bromide found per hundred cubic centimeters of blood after treatment

\begin{tabular}{l|c|c|c}
\hline & \multicolumn{3}{|c}{ Mean bromide level under } \\
\cline { 2 - 4 } & meprobamate & Tranquil & placebo \\
\hline Bromide (mg. per cent) . . . . . . & 3.98 & $40.76^{*}$ & 4.24
\end{tabular}

* Bromide levels under Tranquil ranged to a high of $61 \mathrm{mg}$. per cent.

B. Magnitude and significance of differences in blood bromide level for the different contrasts in treatment

\begin{tabular}{ll|c|c|c}
\hline & & \multicolumn{3}{|c}{ Significance of difference under } \\
\cline { 3 - 5 } & & $\begin{array}{c}\text { Teprobamate } \\
\text { vs. placebo }\end{array}$ & $\begin{array}{c}\text { Tranquil } \\
\text { vs. placebo } \\
\text { vs. } \\
\text { meprobamate }\end{array}$ \\
\hline Bromide . . . . . . . . . . . & -0.18 & $15.73 * *$ & $13.16^{* *}$
\end{tabular}

** Significant beyond the $1 \%$ level of probability.

Table 6. Mean check list ratings for patients under meprobamate, Tranquil, and placebo

\begin{tabular}{l|l|l|c}
\hline \multirow{2}{*}{ Cheok list dimension } & \multicolumn{3}{|c}{ Mean rating under } \\
\cline { 2 - 4 } & meprobamate & Tranquil & placebo \\
\hline
\end{tabular}

Ratings of patient by himself

Semantic differential (lower score indicates more):

Potent . . . . . . . . . . .

High evaluation . . . . . . .

Active . . . . . . . . . .

4.51

3.05

3.42

4.70

3.22

3.8

4.69

3.20

3.62

Ratings of patient by himself

Adjective check list (higher score indicates more):

A. Concentration .

B. Activation vs. deactivation

C. Anxiety . . . . . . . . .

D. Subject-reported symptoms .

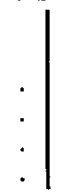

6.5

19.1

19.8

17.1

Ratings of patient by other observer

Adjective check list (higher score indicates more):

A. Concentration .

B. Deactivation vs activatior

B. Deactivation va. activation . .

D. Anxiety - $\cdot \cdot \cdot \cdot \cdot \cdot \cdot \cdot \cdot$
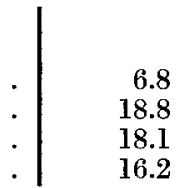

Discrepancy between self and other ratings

\section{Adjective check list:}

B. Activation deactivation.

C. Anxiety vs. deactivation .

D. Subject-reported symptoms .
0.3

0.3

1.7

0.9
$-0.3$

1.0

0.5

0.6 
Table 7. Magnitude and significance of differences in check list scores for the different contrasts in treatment

\begin{tabular}{l|c|c|c}
\hline \multirow{2}{*}{ Check list dimension } & \multicolumn{3}{|c}{ Significance of difference (C. R) under } \\
\cline { 2 - 4 } & $\begin{array}{c}\text { meprobamate } \\
\text { vs. placebo }\end{array}$ & $\begin{array}{c}\text { Tranquil } \\
\text { vs. placebo }\end{array}$ & $\begin{array}{c}\text { meprobamate } \\
\text { vs. Tranquil }\end{array}$ \\
\hline
\end{tabular}

Ratings of patient by himself

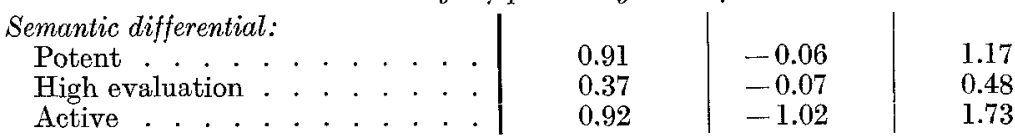

Ratings of patient by himself

\begin{tabular}{l|r|r|r} 
Adjective check list: & & \\
A. Concentration . . . . . . & -0.60 & -1.4 & -0.73 \\
B. Activation vs. deativaction. . & -0.14 & -0.70 & -0.55 \\
C. Anxiety . . . . . . . . & 1.59 & 0.75 & 1.36 \\
D. Subject-reported symptoms . . & 1.24 & 1.24 & 0.17
\end{tabular}

Ratings of patient by other observer
Adjective check list:
A. Concentration . . . . . . -0.29
B. Activation vs. deactivation . . -0.19
0.30
$-1.60$
$-0.60$
C. Anxiety ......... . $\frac{-1.96 *}{-2.55}$
$-2.08$
$-0.93$
$-1.62$
D. Subject-reported symptoms . .
$2.74 * *$
$\overline{3.04} * *$
$\overline{0.28}$

Discrepancy between self and other ratings

Adjective check list:
A. Concentration
B. Activation $\nabla s$ deactivation .
C. Anxiety . . . . . . . . . .
D. Subject-reported symptoms . .
0.00
0.00
$2.58 * *$
1.20
-0.25
0.78
1.33
0.54
0.34
-0.77
1.30
0.79

|

1.C.R.'s for the neurotic subgroup are reported only when they are discrepant from C.R.'s for the total group.

* Significant beyond the $5 \%$ level of probability.

** Significant beyond the $1 \%$ level of probability.

\section{Discussion}

Behavioral Tests. The discrepancies in results between the present and previous studies (Marquis et al.; KELLY et al. 1958a) of the behavioral effects of meprobamate indicate that these results should be evaluated with extreme caution. For the first time in the series of experimental studies of meprobamate with which the authors have been associated, some psychomotor effects appear to have been detected on the complex driver task. In this study meprobamate produced a slight, but significant, slowing of reaction time (of the order of a $4 \%$ decrement), coupled with a slight decrease in accuracy at fast speed. Of three experiments employing the driving test, this result has appeared 
only in the experiment that tested the effects of meprobamate on anxious patients.

Other experiments on meprobamate's effects on driving skills (MELANDER 1957) and on psychomotor performance (REITAN 1957; KoRNETSKY 1958) have confirmed our previous findings of little or no effects, with the single exception of a study by Loomis and WEST (1958), in which eight subjects showed slight $(10 \%)$ but statistically significant decrements in an index of driving proficiency after a single $(400 \mathrm{mg}$.) dose of meprobamate. One possibility that presents itself is that, because Looms and West tested an extremely small group of subjects in their experiment, a sample biased toward neuroticism might have been unwittingly employed, and characterized as "normal".

The actual mechanism of meprobamate's action on behavior may be clarified by the increase in accuracy of time estimation found in the present study when a distracting and misleading influence (a metronome beating at 100 per minute) was introduced. Possibly meprobamate aids the patient in concentrating, in cutting out and selecting from sensory inputs. This finding is further confirmed by a pilot study reported by CLARK, in which subjects were asked to perform a task that would occupy them - to copy random letters - and at the same time to attend and respond to a barely audible buzzer. Increase in concentration and the resulting narrowing of attention would lead to poorer performance on this task, and significantly poorer performance was in fact observed under the influence of meprobamate, as contrasted with placebo. Meprobamate's benign effect on phoria might be another indication of this phenomenon. In this test, unless the patient throws himself completely into the task, it is possible for eye convergence to be incomplete. Finally, the decrement in driving performance could result from a change in concentration. On the driving test the patient must first track the car; but second, he must occasionally respond to an extraneous stimulus - the red light. Here again, the subsidiary response, the reaction time, is primarily affected.

As contrasted with meprobamate, Tranquil appears to have a similar, but slightly lessened, effect on driving — leading to a significant slowing of reaction time, accompanied by a slighter, and nonsignificant, decrease in accuracy at high speed. Lateral phoria (near) and time estimations under distraction are significantly poorer under Tranquil than under meprobamate. Within the anxious subgroup, Tranquil has the effect of increasing the speed at which the patient chooses to drive when he is given control of the accelerator of the car, a possible indication of tendencies toward over-confidence or recklessness. Significant shortening of the length of time breath can be held indicates a possibility of undesirable effects. Decreased visual acuity (near) and the preference 
for a slower "hurrying" rate under Tranquil would also seem to be possible impairing factors.

Psychiatric Assessment. Marked effects, for both drugs, were found in the analysis of the variables quantified from the psychiatric assessments. This phase of the study should be examined with caution, however, because of the inherent difficulties in conducting a blind study when the measuring instrument (in this case, the examining psychiatrist) is not objective. Hower, this would appear to have been as little subject to unblinding as any study of this sort. Quantification was not begun until the entire study was completed, so that the psychiatrist worked only with his interview notes; and tipoffs of drug treatments may have been forgotten by this time.

On the whole, the psychiatrist's picture of meprobamate's effect seems clear. Patients appear more rested, less tense, more active, and have better retention. Yet they do not subjectively "feel better", nor do they "like" the drug. No change in their motivation level can be noted. They feel sleepy and sleep more, but this is true predominantly of the normal as opposed to the anxious patients. Appetite is lowered, and the patients feel that more physical effort is required of them to conduct their day-to-day activities.

Tranquil shared with meprobamate the significant general reaction, greater physical effort required, decreased appetite, and feeling of greater drug activity. Again, no change in motivation level was felt, nor any subjective sensation of "feeling better", nor any special "liking" for the drug. Tranquil led to greater sleepiness and longer nighttime sleep; but, whereas for meprobamate this affected primarily the normal subjects, those who would usually not take the drug, for Tranquil this affected primarily the group of anxiety neurotics. Further, whereas meprobamate gave a feeling of greater restfulness, Tranquil did not. Tranquil, in contrast, led to poorer retention and poorer concentration than meprobamate.

Finally, Tranquil led to significant physiological effects of the sort that would be expected from a bromide compound. Significantly more skin and miscellaneous physical changes (dry mouth, bad taste, and, in subjects with seborrhoeic skins, an exacerbation of the acneic condition) occurred under Tranquil, and the blood bromide level was much higher.

Check List Reports. None of the self-reports indicated any statistically significant effects. The factor scores from reports by roommates, good friends, or spouses gave significantly lower activity ratings to the anxious group when under Tranquil, but significantly lower anxiety ratings to the total group when under meprobamate. When patients were characterized for components of behavior that are related to drug effects, both Tranquil and meprobamate led to significantly better 
characterizations. LASKY et al. (1959) have shown that fellow patients in a psychiatric ward appear to be at least as good observers of behavior of one another as the professional workers (nurses, attendants, psychiatrists, psychologists). These results would again appear to confirm the power of this type of non-professional third person observation.

There appears to be a possibility that the meprobamate effect may be specific to the anxious, neurotic patient and the result not of direct impairment of psychomotor skills, but rather of increased ability to concentrate and concomitant lessened ability to shift attention. If this suggestion is tenable, it does not appear to hold for Tranquil, for which our tests give no picture of improved concentration. The most plausible interpretation of these results, then, might be that different mechanisms underlie the behavioral changes produced by these two drugs - that meprobamate decreases anxiety level and increases ability to concentrate, while Tranquil lowers self-watchfulness and judgment and impairs concentration. Resultant behavior and symptomatic changes, though differently caused, appear in certain aspects similar.

\section{Summary}

The effects of chronic administration of (a) $1600 \mathrm{mg}$. meprobamate, (b) five Tranquil tablets (the maximum recommended daily dose), and (c) placebos were examined, in a counterbalanced partially blinded design. Thirty-two subjects, including 23 anxious patients, employed as their own controls, were given behavioral tests, psychiatric interviews, and ratings at the end of each 21 day treatment period.

On the behavioral tests, meprobamate led to a slowing of reaction time in simulated driving at high speed, accompanied by a slight lowering of accuracy, and an improvement in accuracy of time estimations under a distracting influence. Tranquil led to a similar slowing of reaction time at high speed, along with a nonsignificant tendency toward decreased accuracy, and significantly poorer visual acuity and hyperventilation scores.

On psychiatric evaluations, meprobamate led to marked psychological reactions, daytime sleepiness, longer nighttime sleep, greater restfulness, better retention, need for more physical effort, less tension, decreased appetite, and a feeling that the drug was active. Tranquil led to similar effects as to psychological reactions, daytime sleepiness, nighttime sleep, need for more physical effort, decreased appetite, and judgment of drug activity but no increase in restfulness, improved retention, or lessened tension.

Self-ratings did not differentiate between the three treatments. Ratings by observers indicated decreased anxiety under meprobamate and decreased symptoms under both treatments. 


\section{References}

Cattell, R. B.: Handbook for the objective-analytic personality test batteries. Champaign, Illinois: Institute for Personality and Ability Testing 1955.

Clark, W. C.: Personal communication.

Ersenck, H. J.: Cortical inhibiton, figural after-effect, and theory of personality. J. abnorm. soc. Psychol. s1, 94-106 (1955).

Frtedman, M.: Functional cardiovascular disease. Baltimore: Williams \& Wilkins Co. 1947.

Hamition, M.: Psychosomatics. New York: Wiley 1955.

Kelcy, E. L., J. G. Miller, D. G. Marquis, R. W. Gerard and L. Uhr: Continued meprobamate and proclorperazine administration and behavior. Arch. Neurol. Psychiat. (Chicago) 80, 247-252 (1958a). - Personality differences and continued meprobamate and proclorperazine administration. Arch. Neurol. Psychiat. (Chicago) 80, 241-246 (1958b).

KLeEmetr, R. W., T. A. RioH and W. A. Justiss: The effects of alpha-(2-piperidyl) benzhydryl hydrochloride (Meratran) on psychomotor performance in a group of aged males. J. Geront. 11, 165-170 (1956).

KuETN, G. S., and D. KRECH: Cortical conductivity in the brain injured. J. Personality 21, $118-148(1952)$.

KöHLER, W., and H. WALLACH: Figural after-effects in kinesthesis, Miscellanea psychologica, edit. by A. Michotte. Louvain: Institut Superior de Philosophie 1947.

KoRNETSKY, C.: Effects of meprobamate, phenobarbital and dextroamphetamine on reaction time and learning in man. J. Pharmacol. exp. Ther. 128, 216-219 (1958).

Kornetsky, C., O. HUMPhries and E. V. Evarts: Comparison of psychological effects of certain centrally acting drugs in man. Arch. Neurol. Psychiat. (Chjcago) 77, 318-324 (1957).

Lasky, J. J., G. Hover, C. Nord, P. Smith, D. Duffendack and D. W. Bostian: Post hospital adjustment as predicted by staff and by patients. J. cons. Psychol. 23, $213-218$ (1959).

Loomis, T. A., and T. C. WEST: Comparative sedative effects of a barbiturate and some tranquilizer drugs on normal subjects. J. Pharmacol. exp. Ther. 122, $525-531$ (1958).

Marquis, D. G., E. L. Kelly, J. G. Muluer, R. W. Gerard and A. Rapoport: Experimental studies of behavioral effects of meprobamate on normal subjects. An. N.Y. Acad. Sci. 67, 701-711 (1957).

Melander, B.: Psychotechnological investigation of car drivers in model equipment, translated by the Mental Health Research Institute, Ann Arbor, Michigan, from a duft from the Research Division of A/B Kabi, Stockholm 1957.

Mursky, I. A., E. Lmpman and R. R. Grinker: Breath-holding time in anxiety states. Fed. Proc. 5 (1946).

Nowlts, V., and R. F. Grein: A factor analytic study of the domain of mood with independent experimental validation of the factors. Paper read at the Amer. Psychol. Assn., New York, September 1957.

OsGood, C. E.: The nature and measurement of meaning. Psychol. Bull. 49, 197-237 (1952).

REITAN, R. M.: The comparative effects of placebo, Ultran, and meprobamate on psychologic test performance. Antibiot. Med. 4, 158-165 (1957). 


\section{8}

Smith, G. W., L. Uhr, J. C. Polcard and J. G. Miller: An exploratory study of the behavioral effects of suavitil (benactyzine hydrochloride). Univ. Mich. med. Bull. 24, 402-427 (1958).

Steinberg, H.: Changes in time perception induced by an anaesthetic drug. Brit. J. Psychol. 46, 273--279 (1955).

TAYLOR, JANET A.: A personality scale of manifest anxiety. J. abnorm. soc. Psychol. 48, 285-290 (1953).

Uhr, L., and J. G. MtlukR: An experimental study of the behavioral effects of isothipendyl hydrochloride (Theruhistin). (In press.)

WeCHSter, D.: The measurement of adult intelligence, 3rd edit. Baltimore: Williams \& Wilkins Co. 1944.

Leonard Uhr, Ph. D. (Associate Research Psychologist)

John C. Pollard, M.B., B.S. (London) (Associate Research Psychiatrist, and Instructor in Psychiatry)

James G. Miller, M.D., Ph.D. (Professor of Psychiatry and Paychology and Director), Mental Health Research Institute, The University of Michigan Ann Arbor, Michigan/USA 